\title{
Electron Paramagnetic Resonance Study of the Paramagnetic Center in Gamma-Irradiated Sulfanilic Acid Single Crystal
}

\author{
B. CAliskan ${ }^{a, *}$ And A.C. CAliskan ${ }^{b}$ \\ ${ }^{a}$ Department of Physics, Faculty of Arts and Science, Pamukkale University, 20070, Kinikli, Denizli, Turkey \\ ${ }^{b}$ Department of Chemistry, Faculty of Science, Gazi University, 06500, Ankara, Turkey
}

(Received October 12, 2018; in final form February 8, 2019)

\begin{abstract}
Gamma-irradiated sulfanilic acid $\left(\mathrm{C}_{6} \mathrm{H}_{7} \mathrm{NO}_{3} \mathrm{~S}\right)$ single crystals were analyzed by electron paramagnetic resonance spectroscopy at $120 \mathrm{~K}$ temperature. The irradiation was carried out at room temperature using a ${ }^{60}$ Co-gamma source. EPR spectra of gamma-irradiated sulfanilic acid single crystals were obtained by rotating the magnetic field for three different orientations of the crystal. The paramagnetic center formed in the gammairradiated sulfanilic acid single crystal was determined by examining of the EPR spectra. The EPR spectra of this compound have been found to be temperature independent. The principal values of the hyperfine structure constants of the unpaired electron, and the principal values of the $g$-tensor and direction cosines of the radiation damage centers are calculated. The values were compared with those in the literature, and the results were found to be consistent.
\end{abstract}

DOI: 10.12693/APhysPolA.135.480

PACS/topics: EPR, sulfanilic acid $\left(\mathrm{C}_{6} \mathrm{H}_{7} \mathrm{NO}_{3} \mathrm{~S}\right)$, spectroscopic splitting factor, hyperfine coupling constant, radiation damage center

\section{Introduction}

Charged particles are a directly ionizing radiation group. These particles include energetic electrons (negatrons), positrons, protons, alpha particles, charged mesons, muons, and heavy ions (ionizing atoms). This type of ionizing radiation interacts primarily with matter via the Coulomb force. Particles push or attract electrons from atoms and molecules due to their charges. Uncharged particles form an indirectly ionizing radiation group. Best examples for indirectly ionizing radiation type are photons above $10 \mathrm{keV}$ (X-rays and gammarays) and all neutrons [1]. Ionizing radiation gives rise to charged particles (molecular ions and electrons) and excited molecules in a substance [2]. Radiation breaks bonds between atoms in molecules. The deterioration of the bonds occurs in two ways. If the bonds are broken homolytically (paramagnetic), free (neutral) radicals will form. If the bonds are broken heterolytically (diamagnetic), ionic fragments (charged radicals) are formed [3].

Use of ionizing radiation in sterilization of medicinal products, such as catheters, syringes, drug and drug raw materials, is a new technology alternative to heat and gas exposure sterilization [4-7]. The advantages of sterilization by irradiation include high penetrating power, low measurable residues, small rise in temperature, and the fact that there are fewer variables to control $[8,9]$. Thus, sterilization can be carried out on the finally packaged product and is applicable to heat-sensitive drugs. Irradiation produces new radiolytic products. To prove the

*corresponding author safety of radiosterilization, it is important to determine physical and chemical features of the radiolytic products, and elucidate the mechanism of radiolysis. Thus, it is desirable to establish a method to discriminate between irradiated and unirradiated drugs. Electron spin resonance (ESR) spectroscopy appears to be well suited for determination of free radical concentrations in complex media and so, it can be used to detect and distinguish between irradiated drugs from unirradiated ones [10-13].

Sulfanilic acid, a typical representative of aromatic sulfonated amines, is widely used as an important intermediate in production of azo-dyes, plant protectives, and pharmaceuticals [14]. Sulfanilic acid possesses several good features of the good dosimeter and is characterized by its simple spectrum. Although its sensitivity is less than that of alanine, it could be pressed into pellets purely without need to a binder, and hence more homogeneity could be achieved. Sulfanilic acid is nearly tissue equivalent which enables its use in radiation therapy dosimetry, also it is isotropic and its detection limit is about $100 \pm 30 \mathrm{mGy}$. Sulfanilic acid EPR signal intensity shows noticeable stability for a sufficient time, which enables its use as a transfer dosimeter. Sulfanilic acid deserves further studies in order to be established as a common radiation dosimeter using EPR [15].

In the present study, it was discussed the structure of the free radical in gamma irradiated sulfanilic acid single crystals. The trapped free radical in the compound was examined by the EPR method at $120 \mathrm{~K}$. The single crystal of gamma-irradiated sulfanilic acid has not been studied previously by the EPR method. Therefore, EPR analysis of the sulfanilic acid single crystal was carried out. The experimental data have been confirmed by the theoretical data obtained from the simulation. 


\section{Experimental design}

The sulfanilic acid single crystals were grown in the laboratory by slow evaporation of concentrated acetic acid solution. The sulfanilic acid crystals belong to the orthorhombic, $P c a 2_{1}$ space group and the unit cell dimensions are $a=7.5113(14) \AA, b=7.2791(13) \AA$, $c=13.898(3) \AA, \alpha=90^{\circ}, \beta=90^{\circ}, \gamma=90^{\circ}$. The unit cell contains four molecules $(Z=4)$ [16].

The crystals were irradiated at room temperature with an absorbed dose of about $280 \mathrm{kGy}$ with a ${ }^{60} \mathrm{Co}-\gamma$ ray source. Gamma irradiation was carried out with SVST Co-60-1 type tote-box gamma radiation source capable of continuous and intermittent irradiation at the Turkish Atomic Energy Authority (TAEK) Sarayköy Nuclear Research and Training Center. The EPR spectra were recorded with a Bruker EMX 081 EPR Spectrometer using $0.633 \mathrm{~mW}$ microwave power. EPR work was done for different microwave power values. Step-by-step examination was performed between 0.01 and $20 \mathrm{~mW}$. At higher power values, however, the result was not very good. It was seen that the best EPR signal was received at a power of $0.633 \mathrm{~mW}$. In the EPR spectrometer, $\mathrm{TE}_{102}$ standard rectangular resonator was used. The modulation frequency of the magnetic field was $100 \mathrm{kHz}$ and the modulation amplitude was $2 \mathrm{G}$. The single crystals were mounted on a goniometer and the spectra were recorded in three mutually perpendicular planes by rotating the crystals around $a, b$ and $c$ axes at $10^{\circ}$ intervals from $0^{\circ}$ to $180^{\circ}$. The low temperature measurements were carried out using a Bruker temperature control unit at $120 \mathrm{~K}$.

\section{Results}

The EPR analysis was carried out at $120 \mathrm{~K}$. At this temperature, it was tried to prevent the damping of the radical. Three mutually orthogonal axes of sulfanilic acid single crystals were investigated with 10 degree rotation steps under magnetic field effect. As a result of the analysis of the obtained EPR spectra, the type and the number of the hyperfine splittings did not change in the three axes. However, the hyperfine coupling constants and the spectroscopic splitting factor exhibit anisotropic change depending on the angle. There were 13 partially resolved hyperfine lines in the three axes, and this number has protected itself. Figure 1 shows the molar structure of

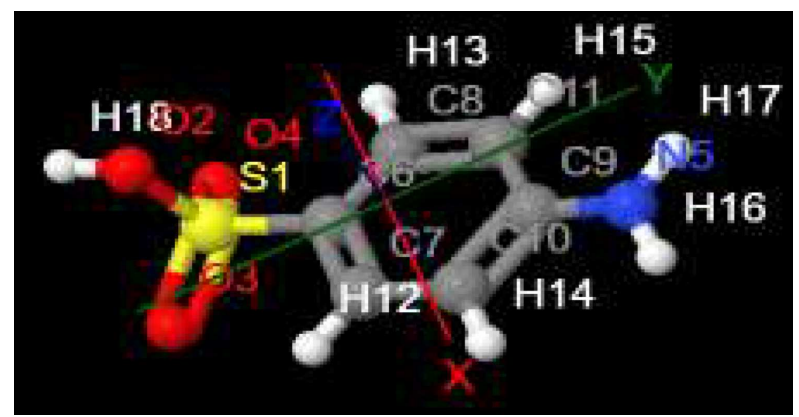

Fig. 1. Molecular structure of sulfanilic acid.<smiles>O=S(=O)(O)c1ccc(I)cc1Nc1ccccc1</smiles><smiles>c1ccccc1</smiles>

Fig. 2. Structure of the radical observed in sulfanilic acid single crystal.
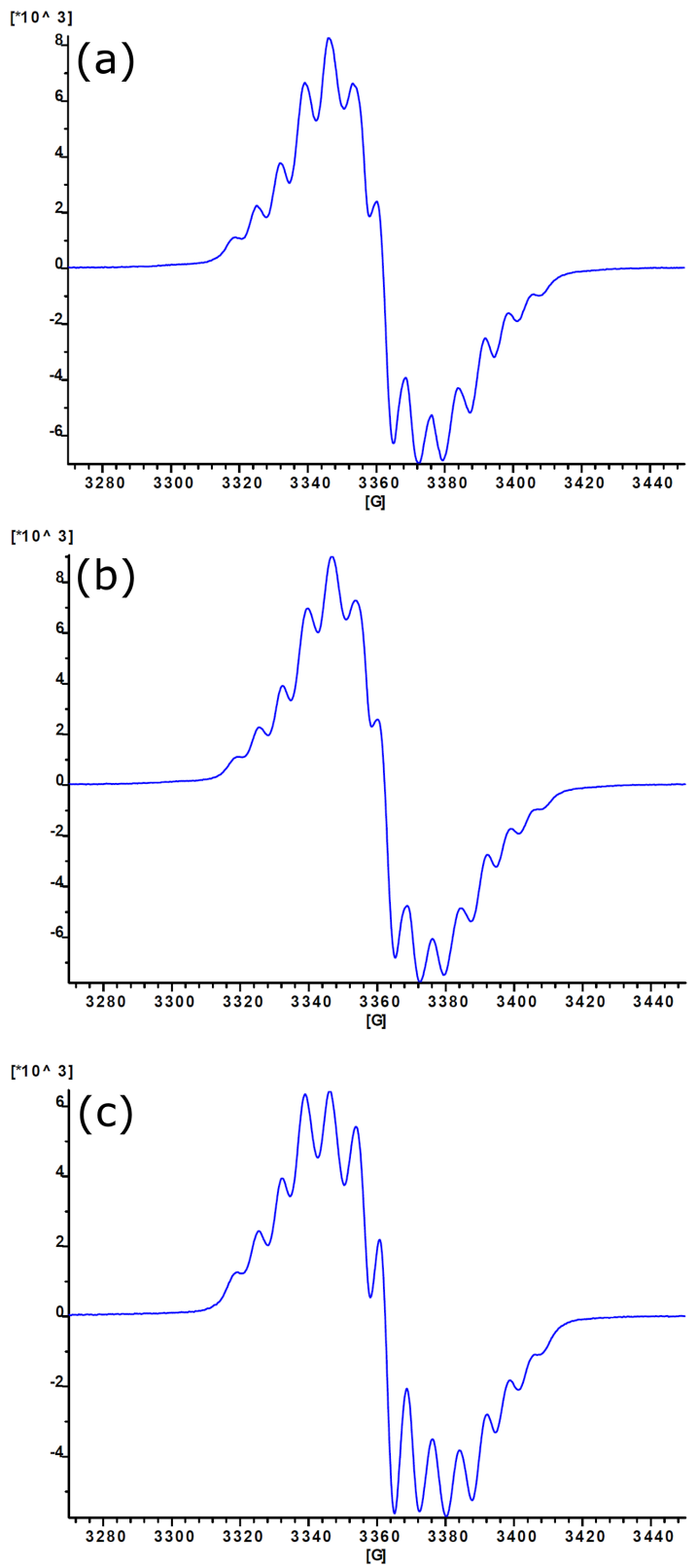

Fig. 3. EPR spectra of gamma irradiated in sulfanilic acid single crystal at $120 \mathrm{~K}$ when the magnetic field is in (a) the $a b$ plane at an angle $0^{\circ}$ towards the axis, (b) the $a c$ plane at an angle $160^{\circ}$ towards the axis, (c) the $b c$ plane at an angle $180^{\circ}$ towards the axis. 
sulfanilic acid, and Fig. 2 shows the structure of the radical observed in sulfanilic acid single crystal. Figure 3 shows spectrum examples taken from three separate axes. These selected spectra are preferred because they have the sharpest and best resolution.

The simulations of the EPR spectra were carried out using the Win-EPR software. The simulation values of the hyperfine coupling constants of the simulated spectra in Fig. 4 are given in Table I. These parameters were slightly modified untill a reasonable agreement between simulated and experimental spectra were reached.

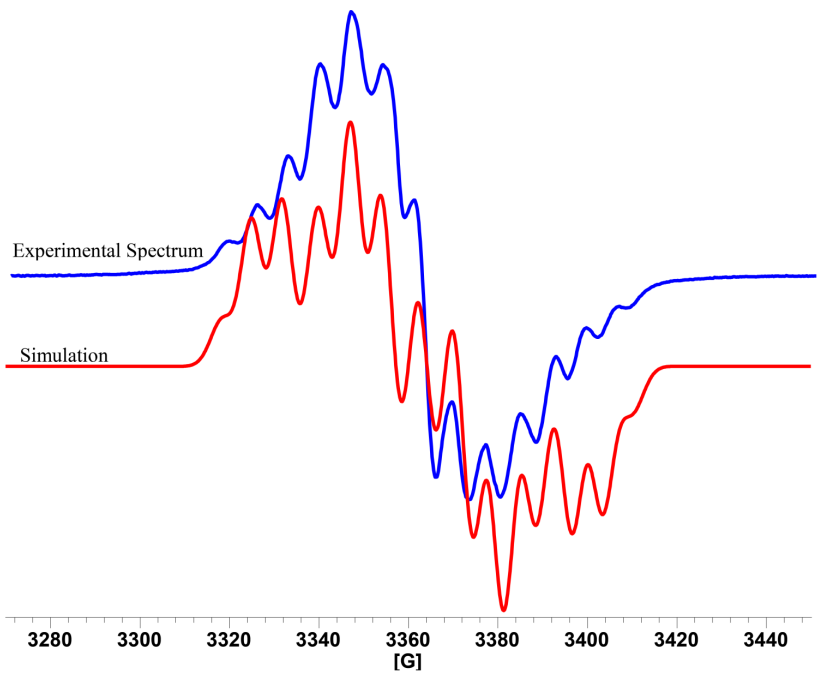

Fig. 4. Experimental and simulated EPR spectra of gamma irradiated sulfanilic acid single crystal at $120 \mathrm{~K}$ when the magnetic field is in the $a b$ plane at an angle $0^{\circ}$ towards the axis.

TABLE I

EPR parameters of simulated spectrum.

\begin{tabular}{l|c}
\hline \hline \multicolumn{1}{c|}{ Parameter } & Value \\
\hline$A_{\mathrm{NH}_{2}}^{\mathrm{N}}$ & $0.925 \mathrm{mT}$ \\
$A_{\mathrm{NH}}^{\mathrm{H}} \cong A_{\mathrm{H}(13)}$ & $2.178 \mathrm{mT}$ \\
$A_{\mathrm{H}(12)} \cong .692 \mathrm{mT}$ \\
$A_{\mathrm{H}(14)} \cong A_{\mathrm{H}(15)}$ & $0.56 \mathrm{mT}$ \\
center field & $336.348 \mathrm{mT}$ \\
$\nu$ & $9.438 \mathrm{GHz}$ \\
line width & $0.575 \mathrm{mT}$
\end{tabular}

The EPR parameters belonging to the radical observed in sulfanilic acid are included in Table II. The angular variations of $A$-values and the $g$-value of the radical in sulfanilic acid single crystal at $120 \mathrm{~K}$ are shown in Figs. 5-8.

Table II. The EPR parameters of the radical observed in sulfanilic acid at $120 \mathrm{~K}$. (Note: The errors are estimated to be \pm 0.00005 and $\pm 0.005 \mathrm{mT}$ for all the calculated $g$ - and $A$-values, respectively.)

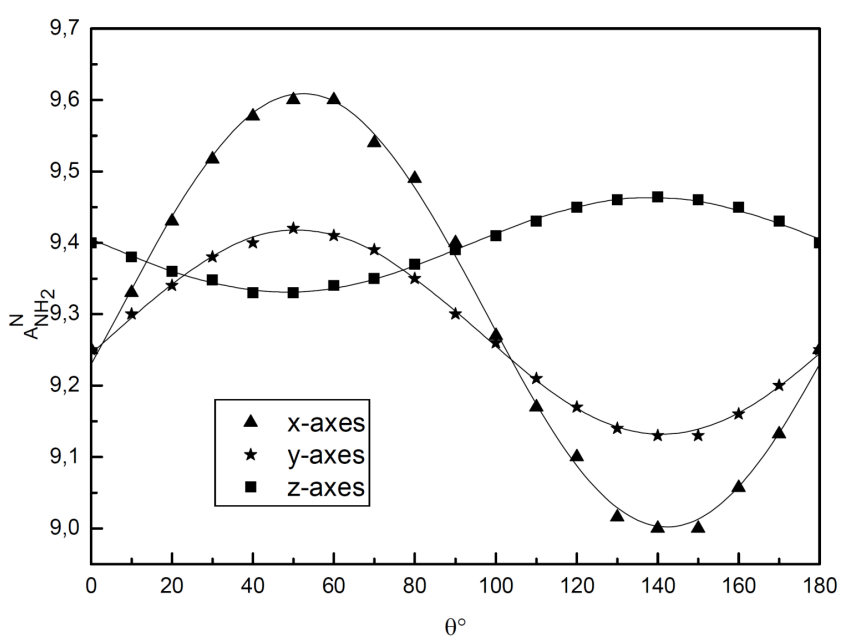

Fig. 5. Angular variation of the $A_{\mathrm{NH}_{2}}^{\mathrm{N}}$-tensor of the radical observed in sulfanilic acid single crystals at $120 \mathrm{~K}$

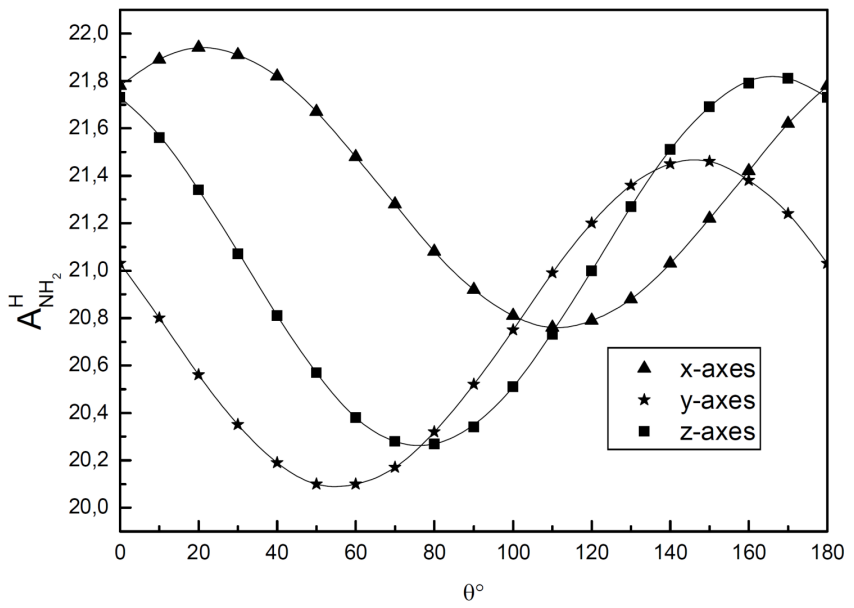

Fig. 6. As in Fig. 5, but for the $A_{\mathrm{NH}_{2}}^{\mathrm{H}}$-tensor.

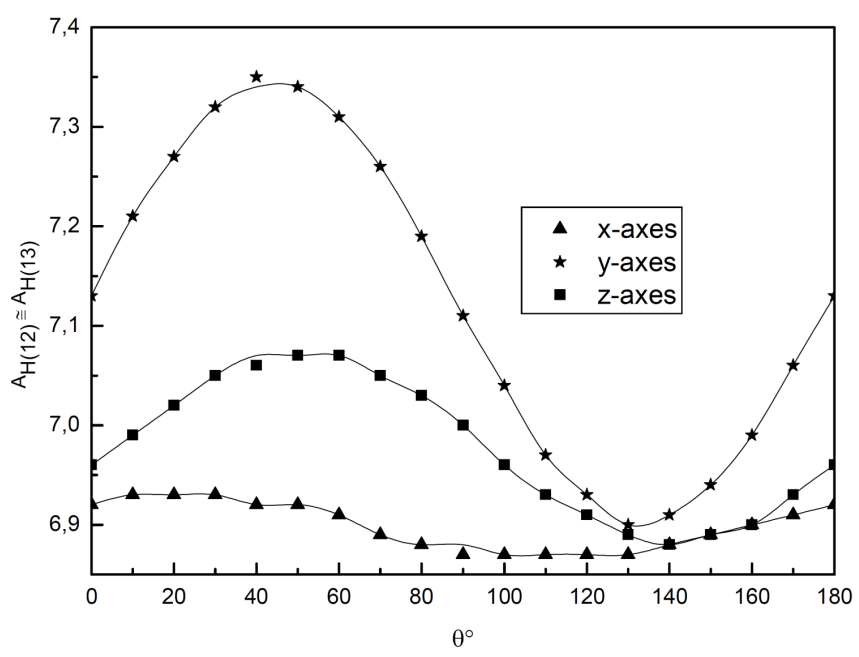

Fig. 7. As in Fig. 5, but for the $A_{\mathrm{H}(12)} \cong A_{\mathrm{H}(13)^{-}}$ tensor. 


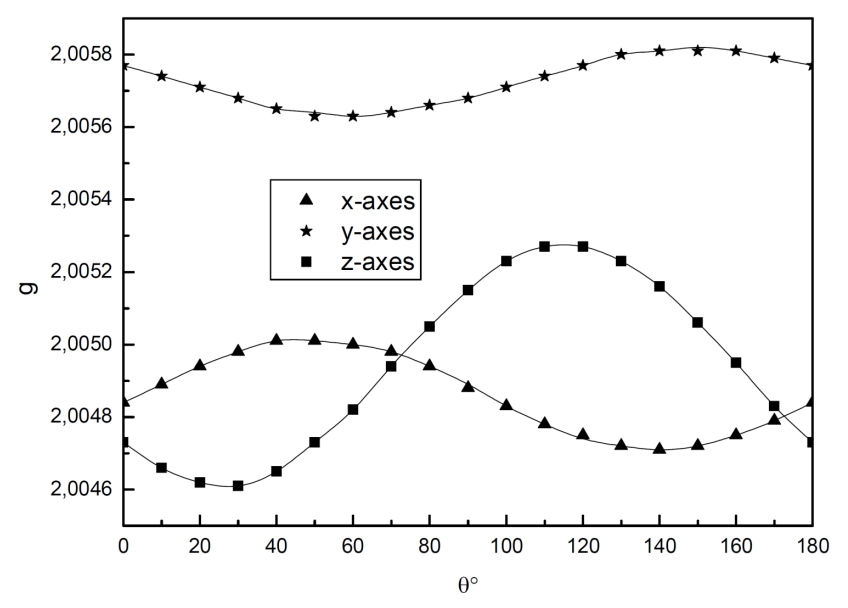

Fig. 8. As in Fig. 5, but for the $g$-tensor.

TABLE II

The EPR parameters of the radical observed in sulfanilic acid at $120 \mathrm{~K}$. (Note: The errors are estimated to be \pm 0.00005 and $\pm 0.005 \mathrm{mT}$ for all the calculated $g$ - and $A$ - values, respectively).

\begin{tabular}{c|l|rrr}
\hline \hline $\begin{array}{c}\text { Radical } \\
\text { parameters }\end{array}$ & \multicolumn{1}{|c|}{$\begin{array}{c}\text { Principal } \\
\text { values }\end{array}$} & \multicolumn{3}{|c}{ Direction cosines } \\
\hline & $A_{x x}=0.963$ & 0.127699 & -0.909771 & -0.394982 \\
$A_{\mathrm{NH}_{2}}^{\mathrm{N}}[\mathrm{mT}]$ & $A_{y y}=0.938$ & 0.750971 & 0.348830 & -0.560678 \\
& $A_{z z}=0.896$ & 0.647870 & -0.225022 & 0.727757 \\
& $A_{\text {iso }}=0.932$ & & & \\
\hline & $A_{x x}=2.2$ & 0.467429 & 0.292170 & 0.834354 \\
$A_{\mathrm{NH}_{2}}^{\mathrm{H}}[\mathrm{mT}]$ & $A_{y y}=2.091$ & -0.614377 & 0.785994 & 0.068956 \\
& $A_{z z}=2.024$ & -0.635651 & -0.544840 & 0.546898 \\
& $A_{i s o}=2.105$ & & & \\
\hline \multirow{3}{*}{$A_{\mathrm{H}(12)} \cong$} & $A_{x x}=0.728$ & 0.738905 & 0.109350 & -0.664878 \\
$A_{\mathrm{H}(13)}[\mathrm{mT}]$ & $A_{y y}=0.692$ & 0.220785 & 0.892978 & 0.392231 \\
& $A_{z z}=0.679$ & 0.636611 & -0.436616 & 0.635683 \\
$A_{\mathrm{H}(14)} \cong$ & $A_{i s o}=0.7$ & & & \\
$A_{\mathrm{H}(15)}[\mathrm{mT}]$ & $A_{i s o}=0.56$ & & & \\
\hline & $g_{x x}=2.00560$ & 0.864468 & 0.408348 & -0.293168 \\
& $g_{y y}=2.00524$ & -0.351214 & 0.073386 & -0.933415 \\
& $g_{z z}=2.00469$ & -0.359643 & 0.909872 & 0.206857 \\
& $g_{i s o}=2.00518$ & & &
\end{tabular}

\section{Discussion}

The radiation damage center formed in gammairradiated sulfanilic acid single crystal was studied by EPR method at $120 \mathrm{~K}$. It was observed that the EPR parameters of the radical formed in the sulfanilic acid single crystal exhibited anisotropic property. The hyperfine splittings are determined by the interaction of the $\mathrm{N}(5)$ nitrogen nucleus with the unpaired electron, the interaction of the two magnetically equivalent $\mathrm{H}(16)$ and $\mathrm{H}(17)$ hydrogen nuclei with the unpaired electron, the interaction of the two magnetically equivalent $\mathrm{H}(12)$ and $\mathrm{H}(13)$ nuclei with the unpaired electron, and the interaction of the two magnetically equivalent $\mathrm{H}(14)$ and $\mathrm{H}(15)$ nuclei with the unpaired electron. The $\mathrm{NH}_{2}$ fragment in the structure shows its effect in the spectra. Therefore, the point where the bond can break is not in this region.
The weakest point in the structure is the only bond between $\mathrm{S}(1)$ and $\mathrm{C}(6)$. The result of the disconnection of this bond, the unpaired electron is trapped on $\mathrm{C}(6)$.

In the hydroxylammonium salts, the hyperfine constants were found to be almost isotropic with an average $a_{\mathrm{N}}=0.7 \mathrm{mT}, a_{\mathrm{H}}=2 \mathrm{mT}$ for the $\dot{\mathrm{NH}}_{2}$ radical, and $a_{\mathrm{N}}=1.15 \mathrm{mT}, a_{\mathrm{H}}=1.1 \mathrm{mT}$ for the $\dot{\mathrm{N}}_{2} \mathrm{H}_{4}^{+}$radical [17]. In the previous studies, for the $\mathrm{N}_{2}$ radical, the theoretical value of the hyperfine structure constant of $\mathrm{N}$ is $1.008 \mathrm{mT}$ and the experimental value is $1.03 \mathrm{mT}$ [18], the theoretical value of the hyperfine constant of $\mathrm{H}$ is $-1.704 \mathrm{mT}$ and the experimental value $-2.39 \mathrm{mT}$ [19], respectively. The hyperfine coupling constants of the nitrogen and the hydrogen were determined as $a_{\mathrm{N}}=1.39 \mathrm{mT}, a_{\mathrm{H}}=2.10 \mathrm{mT}$ for the $\dot{\mathrm{NH}}_{2}$ radical in glycine [20]. In a theoretical study, after the optimization for $\mathrm{NH}_{2}$ using a minimal basis set of SCF atomic orbital, expressed as a linear combination of Gaussian orbitals, the calculated hyperfine coupling constants are $a_{\mathrm{H}}=-2.233 \mathrm{mT}$ and $a_{\mathrm{N}}=0.846 \mathrm{mT}[21]$. For the $\mathrm{H}_{2} \mathrm{CN}$ radical, the theoretical value of $\mathrm{N}$ is $0.961 \mathrm{mT}$, and the experimental value is $0.95 \mathrm{mT}$, the theoretical value of the hyperfine structure of $\mathrm{H}$ is $5.479 \mathrm{G}$ and the experimental value is $9.21 \mathrm{mT}[22]$. For the $\mathrm{H}_{2} \mathrm{NO}$ radical, the theoretical value of the hyperfine structure constant of $\mathrm{N}$ is $2.791 \mathrm{mT}$ and the experimental value is $1.19 \mathrm{mT}$, the theoretical value of the hyperfine structure of $\mathrm{H}$ is $-0.844 \mathrm{mT}$ and the experimental value is $1.19 \mathrm{mT}$ [23]. The hyperfine constants of the $\mathrm{NH}_{2}-\mathrm{HF}$ complex are $a_{\mathrm{N}}=1.20 \mathrm{mT}$, $a_{\mathrm{H}}=2.40 \mathrm{mT}$, and $a_{\mathrm{F}}=0.70 \mathrm{mT}$. The observed EPR spectrum by photolysis of $\mathrm{Ar}-\mathrm{F}_{2}-\mathrm{NH}_{3}$ mixtures at $15 \mathrm{~K}$ corresponds to two triplet groups with the hyperfine coupling constant $a_{\mathrm{N}}=1.05$ and $a_{\mathrm{H}}=2.40 \mathrm{mT}$, and $g=2.0058$. The observed EPR spectrum by annealing of Ar- $\mathrm{F}_{2}-\mathrm{NH}_{3}$ mixtures at $15 \mathrm{~K}$ corresponds to two triplet groups with the hyperfine coupling constant $a_{\mathrm{N}}=1.20$ and $a_{\mathrm{H}}=2.40 \mathrm{mT}$ [24]. In the aminoxyl radical, the hyperfine structure constants of the unpaired electron with the nitrogen core and with the two equivalent hydrogen nuclei were found to be $a_{\mathrm{N}}=1.44 \mathrm{mT}$ and $a_{\mathrm{H}}=2 \mathrm{mT}$, respectively [25]. The hyperfine coupling constants of the nitrogen nucleus for various solvents were found to be between 1.379 and $1.596 \mathrm{mT}$ [26]. In the EPR study of gamma-irradiated potassium hydroquinone monosulfonate single crystal, the hyperfine coupling constant of the ring hydrogen was found as $0.568 \mathrm{mT}$ [27].

Both Maghraby and Tarek [15] and Alzimami et al. [28] have studied the dosimetric effect of $\mathrm{SO}_{3}^{-}$formed in sulfanilic acid under ionizing radiation. Maghraby and Tarek [15] used a ${ }^{137} \mathrm{Cs}$-gamma source for samples irradiation. 255 Gy gamma-irradiated sulfanilic acid EPR spectra were recorded at room temperature. Alzimami et al. [28] used a ${ }^{60} \mathrm{Co}$-gamma source for samples irradiation. The samples were irradiated at doses lower than $100 \mathrm{kGy}$. The radiation dose range for sulfanilic acid is between 5.05 and 202.26 Gy [28]. In both studies, the $g$-value of the irradiated sulfanilic acid spectrum is approximately $2.0053 \pm 0.00017$ and the EPR spectrum 
consists of a singlet [15]. The work of both Maghraby and Tarek [15] and Alzimami et al. [28] is about the EPR dosimetry. Both studies show that the EPR analysis was performed at room temperature.

In these studies, the EPR spectrum of sulfanilic acid is in the form of a single signal and does not reveal the hyperfine structure splittings it contains. In our study, EPR spectra were taken at low temperature. Low temperature provides trapping of the single electron region. Thus, the effect of hyperfine splittings is retained for a longer period of time. In our EPR study, the hyperfine structure splittings are not single signal, unlike the other two studies, and it appears that there are thirteen partially resolved hyperfine structure splittings. However, the radical in our work is completely different from the radical in those works. The amount of radiation applied in our work is higher than the amount of radiation used in those studies. Unlike those studies, the sample we use is a single crystal.

Because of the radical formed in gamma-irradiated sulfanilic acid single crystal, the spectra exhibit 13-lines with intensity ratios $1: 2: 2: 4: 6: 6: 6: 6: 6: 4: 2: 2: 1$. Owing to the nitrogen atom, the spectra exhibit a triplet (1:1:1). Then, due to the two magnetically equivalent $\mathrm{H}(16)$ and $\mathrm{H}(17)$ hydrogen nuclei, the spectra exhibit a triplet $(1: 2: 1)$. Due to the two magnetically equivalent $\mathrm{H}(12)$ and $H(13)$ nuclei, the spectra exhibit a triplet $(1: 2: 1)$. Owing to the two magnetically equivalent $\mathrm{H}(14)$ and $\mathrm{H}(15)$ nuclei, the spectra exhibit a triplet (1:2:1). The spectrum showed thirteen hyperfine lines due to superimposition of hyperfine splitings. For the paramagnetic center formed in gamma-irradiated sulfanilic acid single crystal, the average values of the $g$-factor and the hyperfine coupling constants were obtained as $g=2.00518, a_{\mathrm{NH}_{2}}^{\mathrm{N}}=0.932 \mathrm{mT}, a_{\mathrm{NH}_{2}}^{\mathrm{H}}=2.105 \mathrm{mT}$, and $a_{\mathrm{H}(12)} \cong a_{\mathrm{H}(13)}=0.7 \mathrm{mT}, a_{\mathrm{H}(14)} \cong a_{\mathrm{H}(15)}=0.56 \mathrm{mT}$ respectively, and these values are also in agreement with the literature values given for these radicals.

\section{Conclusions}

The investigation of single crystals of gammairradiated sulfanilic acid by the EPR method showed the presence of a single carbon-centered radical. The observed free radical was obtained by cleavage of $\mathrm{C}-\mathrm{S}$ bond. The radical is stable. The hyperfine structure constants and the spectroscopic splitting factor of the compound were calculated and their principal axis values and direction cosines were found. It is seen that the hyperfine structure constants and $g$-value are anisotropic. Experimental data have also been confirmed by simulation studies.

\section{Acknowledgments}

This work was supported by the BAP of Pamukkale University (grant no. 2012FBE037).

\section{References}

[1] R.N. Cherry Jr., Part VI - General Hazards, Radiation: Ionizing, Introduction, Online Edition: Encyclopaedia of Occupational Health and Safety, Ch. Ed. R.N. Cherry Jr..

[2] S.Y. Pshezhetskii, A.G. Kotov, V.K. Milinchuk, V.A. Roginskii, V.I. Tupikov, EPR of Free Radicals in Radiation Chemistry, Wiley, New York 1974.

[3] M. Bersohn, J.C. Baird, An Introduction to Electron Paramagnetic Resonance, Benjamin, New York 1966, p. 190.

[4] G.P. Jacobs, J. Biomater. Appl. 10, 59 (1995).

[5] B.D. Reid, PDA J. Pharm. Sci. Technol. 49, 83 (1995).

[6] B. Tilquin, B. Rollmann, J. Chim. Phys. 93, 224 (1996).

[7] C. Boess, K.W. Bögl, Drug Dev. Ind. Pharm. 22, 495 (1996).

[8] A.L. Fauconnet, J.P. Basly, M. Bernard, Int. J. Pharm. 144, 123 (1996).

[9] J.P. Basly, I. Longy, M. Bernard, Int. J. Pharma. 154, 109 (1997).

[10] M. Gibella, A.-S. Crucq, B. Tilquin, J. Chim. Phys. 90, 1041 (1993).

[11] E.C. Signoretti, L. Valvo, P. Fattibene, S. Onori, M. Pantaloni, Drug Dev. Ind. Pharm. 20, 2493 (1994).

[12] T. Miyazaki, T. Kaneko, T. Yoshimura, A.-S. Crucq, B. Tilquin, J. Pharm. Sci. 83, 68 (1994).

[13] S. Onori, M. Pantaloni, P. Fattibene, E.C. Signoretti, L. Valvo, M. Santucci, Appl. Radiat. Isotop. 47, 1569 (1996).

[14] M. Magony, Acta Biol. Szeged. 48, 65 (2004).

[15] A. Maghraby, E. Tarek, Rad. Meas. 41, 170 (2006).

[16] J.N. Low, C. Glidewell, Acta Crystallogr. C 58, o209 (2002).

[17] F. Köksal, O. Çakir, İ. Gümrükçü, M. Birey, Z. Naturforsch. A 40, 903 (1985).

[18] S.N. Foner, E.L. Cochran, V.A. Bowers, C.K. Jen, Phys. Rev. Lett. 1, 91 (1958).

[19] T. Cole, J. Chem. Phys. 35, 1169 (1961).

[20] D.K. Ghosh, D.H. Whiffen, J. Chem. Soc. 1960 1869 (1960).

[21] T.A. Claxton, Trans. Faraday Soc. 66, 1537 (1970).

[22] M.C.R. Symons, J. Chem. Phys. 55, 1493 (1971).

[23] J.Q. Adams, S.W. Nicksic, J.R. Thomas, J. Chem. Phys. 45, 654 (1966).

[24] I.U. Goldschleger, A.V. Akimov, E.Ya. Misochko, J. Mol. Struc. 519, 191 (2000).

[25] C. Lagercrantz, Free Radic. Biol. Med. 13, 455 (1992).

[26] E.G. Janzen, G.A. Coulter, U.M. Oehler, J.P. Bergsma, Can. J. Chem. 60, 2725 (1982).

[27] B. Caliskan, A.C. Caliskan, E. Er, Radiat. Eff. Def. Sol. 171, 440 (2016).

[28] K.S. Alzimami, A.M. Maghraby, D.A. Bradley, Radiat. Phys. Chem. 95, 109 (2014). 